\title{
Beyond the expected: an enriched learning experience through learner engagement and participation
}

\author{
Estelle Zeeman ${ }^{\mathrm{a}}$ and Marena Lotriet ${ }^{\mathrm{b} *}$ \\ ${ }^{a}$ Department of Drama, University of Pretoria, Pretoria, South Africa; ${ }^{\mathrm{b}}$ Department for \\ Education Innovation, University of Pretoria, Pretoria, South Africa
}

\begin{abstract}
The teaching of classical Greek dramas is integral to drama education at the University of Pretoria. In the past few years these dramas increasingly faced the danger of becoming 'foreign'/irrelevant to modern day students. The introduction of performance practice to teach these dramas brought a whole new dimension to teaching and learning in the course. In this case study we describe how the once stagnant learning environment with the lecturer as sole distributor of knowledge, was reframed to allow for learner engagement and empowerment. We document the particular application of Heathcote's 'mantle of the expert' against three theories of educationally sound learning design. The nature of the learning that resulted is then described, based on an in-depth analysis of qualitative data gathered from two consecutive student cohorts. We conclude that this particular teaching approach not only brought the ancient texts to life, but also succeeded in empowering and motivating students - resulting in a rich learning experience.
\end{abstract}

Keywords: teaching innovation; classical Greek dramas; 'mantle of the expert'; text adaptation; performance practice; holistic student learning

\section{Introduction}

Curriculum review and development in higher education in the broadest sense of the word is a continuous cyclical process of reflection, improvement and implementation. It is often during stages of challenge and risk that opportunities for reflection and improvement present themselves best (Mighty 2009). Our article describes how the teaching of classical Greek dramas (as integral part of drama education at the University of Pretoria) faced the risk of becoming 'foreign' to a new generation of students and how the learning space was innovatively reframed to create an exact opposite outcome.

The particular innovation is presented as a case study within a defined second year course in Drama and Film Studies at the University of Pretoria - taught by the same lecturer for the past number of years. After a description of the innovation as based on the lecturer's (first author) reflective observation and experience, the nature of the learning experience of the students is explored as research unit of analysis.

*Corresponding author. Email: marena.lotriet@up.ac.za 


\section{Research \\ Research design and methodology}

The research design is that of a case study as described above. The results are based on open-ended questionnaires anonymously completed by two consecutive second year groups (2009 and 2010) after completion of the module. In 2009 a total of 56 respondents participated and in 2010 a total of 42 respondents - in both cases around $80 \%$ of the total year group.

The questionnaire consisted of four open-ended questions:

- How did you experience the particular approach to teaching the classics (explain briefly)?

- What (according to you) have you gained (skills, knowledge, insights, attitudes etc.) from this particular approach (things that you feel are useful for you in terms of current studies, your future career, or life in general)?

- What did you learn in terms of classical Greek drama?

- Any other comments?

The open-ended nature of the questions left room for the study to follow the pattern of qualitative inquiry embedded in an interpretivist framework as described by Henning (2004, 1-22).

\section{Data analysis}

Responses from the 2009-group were captured and analysed in ATLAS.ti. Phrases were coded individually and categorised according to emerging themes. Responses from the 2010-group were manually added to the existing categories and in a few instances, new themes and categories were formed. The results of the analysis of both sets of data are described in the sections following the description of the innovation.

\section{Background and innovation}

The course in Drama and Film Studies is taught at the University of Pretoria as a 7 week module at second year level. It consists of three lecture hours per week and covers a selection of classical Greek dramas. Both drama students and non-drama students may enrol for the module. The students are from a culturally diverse background and are aged between 19 and 21 years. In previous years these classes tended to be rather tedious and not very inspiring to the modern day youth. Greek plays were also regarded as strange, 'boring' and difficult to understand (especially seen from an African context). A low attendance figure indicated the need for a new approach.

As part of a teaching improvement process the lecturer experimented with a number of approaches - leading to various cycles of action research (Zuber-Skerrit 1992). One of these approaches included teaching under a big thorn tree. This lead to a critical moment of insight. An incident with a worm dangling from a small branch of the said thorn tree and a passing bird that made a few dives at it, caused opposite reactions from the male and female students respectively - resulting in an argument between the two sexes. The lecturer suddenly realised that she was witnessing drama in the making with the whole class participating and the question arose: 'Why not use 
drama to teach ancient drama?!' Such an approach would fit research done by Coetzee, Munro, and de Boer (2004) who found that drama students seem to tend towards emotional, intuitive, interpersonal and kinaesthetic modes of learning.

\section{A new approach to teaching embedded in a new theoretical framework for learning}

\section{The new approach}

With this new approach of using drama and performance practice to teach drama the intention was to make the classics come to life - no longer to be viewed as ancient tales with little relevance to modern-day society. The particular way it was implemented, was based on the theoretical framework of Heathcote's (Heathcote and Bolton 1995) 'mantle of the expert' - a teaching methodology and philosophy that stresses the importance of allowing students to take important decisions during a learning opportunity in order for them to feel that they are shareholders in the learning. Every student's prior knowledge and experience are furthermore harnessed and integrated into the learning content. Knowledge and understanding is collectively generated and not transmitted - following Freire's (2006, 88-91) notion of 'dialogical teaching' as opposed to of the notion of 'banking education' (72).

Based on the above, the new approach was structured as follows: classes were divided into a number of groups and given a short synopsis of each of the plays selected for the module. Each group then had to choose a play to perform to the rest of the class - not 'as is', but as contemporary adaptations of the classic scripts. Directors were selected from each group to direct the plays and students could choose to focus on a specific part of the play. This allowed them to engage with the play in depth. The idea of the performance was not to judge students' performance skills, but rather the concept they came up with in relation to the criteria for the task.

The following documentation had to be prepared by the performing groups:

- a short class test for the rest of the students on the content of the original play;

- a typed adaptation of their play; and

- a short essay in which they explain:

o why they chose their particular contemporary concept and how it relates to the classic text and to themselves;

what themes they focused on; and

how the performance interfaced with related theoretical concepts that form part of the module.

The latter two documents had to be available to the whole class on the electronic learning management system. The purpose is to provide fellow students with insight into the adaptation and the thought processes that connect the adaptation to the play. In addition each performing group had to select a panel to lead the class discussion after the performance and field questions that may arise from their performance. This meant that the group had to familiarise themselves with the play, its context, and related theoretical paradigms. In turn it was expected from the audience to have read the original play. 
Although not central to the outcomes of the course, performing groups received a credit bearing mark out of 20 for their adaptation by means of a vote from the rest of the class acting as perceptual panel. This contributed to high quality productions with great entertainment value, since students were keen not to disappoint their audience. The best performances had the opportunity to take part in a gala evening for an external audience at the end of the module.

Not only does this method reflect a particular application of Heathcote's (Heathcote and Bolton 1995) 'mantle of the expert', but it reflects a number of educationally sound design principles. Although the authors agree that good design includes aspects of teaching and learning activities, as well as curriculum development, assessment and the alignment of all elements (Biggs 1999), for the purposes of this article, the focus is on the teaching and learning activities design per se.

\section{Sound learning environment design}

The following theories are being used as measures: Nedd Herrmanns' whole brain model; Boud and Prosser (2002) four key areas for learning design; and the constructivist learning theories of Mayes and Freitas (2004), Scheurman and Newmann (1998) and Newmann (2000).

In accordance with Herrmann's (1996, 21) whole brain model for learning, learners were engaged holistically and had the opportunity to develop intellectually, organisationally, emotionally and innovatively. The plays had to be studied, the background researched and concepts explored. Students also had to be innovative and creative in synthesising the new gained knowledge into an original production, whilst interrelating to peers as well as organising and managing their performances.

Boud and Prosser $(2002,240-241)$ point to four key areas which provide the best practice for the development of learning designs (although referring to e-learning, they are also applicable to other learning situations):

- Engaging learners - starting from where learners are, taking into account their prior knowledge/desires and building on their expectations.

- Acknowledging the learning context - the context of the learner, the course and the sites of application of the knowledge being learned.

- Challenging learners - seeking to get learners to participate actively, to use the support of other learners, to take a critical approach to the materials and to go beyond what is immediately provided.

- Providing practice - opportunity to demonstrate what is being learned, to gain feedback, to reflect on learning and to develop confidence through practice.

By allowing students not only to read the Greek plays, but also to create and perform their own contemporary adaptations based on the plays, students were not only actively engaged, but also given the opportunity to operate from within their own framework of existing knowledge. In this case the 'context of the learner', 'the course of which the activity is part' as well as 'the sites of application of the knowledge being' (Boud and Prosser 2002, 240, as quoted above) were fully aligned.

Learners were furthermore challenged far beyond what was 'immediately provided to them' (Boud and Prosser 2002, 240, as quoted above). The research 
component required as part of the process lead them to become 'experts' and more knowledgeable than the rest of their class regarding the play that they have chosen to adapt. This required a critical engagement with, not only the plays and their contexts, but also their value and relevance for today's theatre and performance environment. The performance itself required students to synthesise and integrate all components of the course, think conceptually and foster empathetic engagement with the characters, relationships and situations in the play. These preparations and performances added yet another dimension to the course outcomes and challenge to students, namely that of management, planning and organisation.

The detailed and timely feedback that was given during the class discussion after performances (facilitated by the lecturer) aimed to motivate students to reflect on their learning, to consolidate aspects of the course content, to redirect thinking, to identify problem areas and to provide a profile of student learning up to that point.

The above description clearly fits a design situated in a 'constructivist' learning theory, including 'situative' and 'activity systems' perspectives (as described by Mayes and Freitas 2004, 8-10, 15-21) where constructing of understanding requires both 'interactions with material systems and concepts in the domain' as well as 'interactions in which learners discuss their developing understanding and competence' (Mayes and Freitas 2004, 16). It furthermore seems to escape Scheurman and Newmann's (1998) and Newmann's (2000) critique of many constructivist approaches as not contributing to 'the application of knowledge ... to questions and issues within a particular domain'. It rather confers with their concept of 'authentic intellectual work' in that it includes: the construction of knowledge which entails higher order thinking; disciplined inquiry with regard to deep knowledge and substantive conversation; and value beyond the classroom which relates to students connecting disciplinary content to the world at large.

\section{Course outcomes}

This new approach appeared educationally sound with constant high class attendance figures and the design grounded in pedagogical theories as described above. We, however, wanted to explore the nature of the learning that seemed to reach beyond the expected outcomes for the course as defined by Zeeman (2010):

- Analyse dramas against the background of the socio-historical and cultural attitudes of the time;

- Give a synopsis or report of the historical, cultural, political, economical and creative conditions in ancient Greece;

- Differentiate between the role and status of women in society and how they are portrayed in dramas and on stage;

- Various cross-disciplinary outcomes, such as problem solving, effective teamwork, self management, collecting and using information, effective communication and understanding the interrelatedness of things (South African Qualifications Authority 2005, 9).

The research results are discussed below in terms of the broader themes of students' learning experience, knowledge, skills and emotional/attitudinal gains. From this a picture of rich learning emerges clearly. Quotations taken directly from responses are given in quotation marks. 


\section{A holistic learning experience}

\section{Unique experience}

Although there is no attempt in this study to compare the teaching method under discussion to any other method or course, a number of comments draw upon a direct comparison with other learning experiences and even previous learning experiences of similar kind. In an appreciative tone phrases such as 'unique experience', 'new dimension' and 'extra-ordinary method' are mentioned often - indicating the fact that this approach and related experience was not the norm. Not only do students regard it to be novel, but they seem to appreciate it as an experience that widened their horizons. As one student mentioned: 'By being involved, opened up a whole new sphere of education'.

The teaching approach/learning environment does not only seem to surprise students in comparison to other learning experiences, but also when it comes to their original expectations of what the study of Greek drama might entail. Where they expected the latter to be 'purely theoretical', 'boring' and 'taxing', they experienced it as 'dynamic and hands-on' as well as 'entertaining'. This underlines the clear enjoyment factor that formed part of this experience.

\section{Enjoyment}

On the whole the majority responses provided from both cohorts indicated an overwhelmingly positive reaction. Phrases such as 'Loved it!', 'Awesome!' and 'Fantastic!' were used repetitively by both years' respondents - pointing towards students' overall enjoyment of and affection for the teaching approach. This does not only refer to the performances part of the innovative approach, but also to the discussions afterwards: 'I enjoy class very much, far more interesting to have conversations than to copy notes all lesson long'.

\section{Speaking to student learning styles}

Based on the lecturer's reflection the above forms a stark contrast with student behaviour in previous years of traditional teaching. One possible explanation for the overwhelmingly positive reaction to the new approach as described above might lie in the particular learning styles of the particular group of students as described by Coetzee, Munro, and de Boer (2004). Various responses indicate that this approach speaks to the particular type of students' preference for learning to be creative, emotional, social and actively engaging. The following quote captures this well: 'What better way to learn through acting? What a brilliantly creative way of studying'.

In addition to the above the approach seems to have responded to a clear preference for visual learning: 'It was more interesting visually and one learns faster by seeing the plays than reading it'. Not only does this fit a preferred learning style, but it is also regarded to be asked for by the subject matter: 'It allowed you to see a visual representation of the works that are supposed to be seen in this manner'.

This teaching approach, received with all the enthusiasm described above, faced the danger of being pure entertainment, not focused towards the expected outcomes. While Burnaford, April, and Weiss $(2001,18)$ support the integration of arts into the learning process, they are quick to point out that ' $(\mathrm{t})$ his does not mean that the arts 
should be trivialised into entertainment to lessen the boredom of uninspired teaching'. In the following section, however, it is described how the enthusiasm created by this particular approach reached beyond the feeling of enjoyment.

\section{Impetus for learning}

The approach seems to have provided impetus for learning in that it stimulated deep learning; inspired a desire to learn more; provided challenging engagement; and motivated students both to attend class and to work harder. The many related responses can be summarised by the following: 'It ... encouraged me to think and look deeper than I usually would'.

The above might also explain the numerous responses describing the approach as 'successful', 'effective' and 'educational'. It furthermore addresses Burnaford, April, and Weiss' $(2001,17)$ warning that '(s)imply engaging in the experience of making art is not enough for learning to occur, particularly over the long term' and answers to their call that the contribution of the arts should contribute to cognitive development (18). Exactly how the specific teaching approach contributed to cognitive development is described in more detail in the following sections.

\section{Knowledge gained}

An analysis of the responses reflects that the knowledge that the students perceive to have gained answers to the desired outcomes described under 'Course outcomes' above and more. Many students claim that they have gained knowledge with regards to Greek plays. By deeper analysis of the data this particular knowledge base seems to fall out into a number of categories:

\section{- Structural aspects}

Various responses hint towards the fact that students were able to understand the structural aspects of the plays better. These include character development, the structure and plot of the text, word usage, the restrictions of the text, themes and the fact that they were written 'according to the social background of the era'. The latter links with the insight the students gained in terms of the material that inspired the content of the plays.

- Material that inspired the content of the plays

Students show an appreciation for the fact that the authors sourced a lot from '(t)he stories of the Gods' (Greek mythology) and that they mainly wrote about 'social issues', such as '. . sex, tragedy, death or women empowerment'. They see the dramas studied as being embedded in this socio-historical context. As one student puts it: 'The extent of the male-oriented Greek society and the oppressed women in it and what effect it had on the Greek theatre'.

As result of the choice of plays covered during the two years of this study, it was mainly the role of women in society that was fore-fronted by students as one of the main issues. The following quote sums up the gist of many other responses: 'All women are cunning, clever, manipulative, victims, heroines and villains! Women did 
not have much say in those days but in the classical Greek dramas they are the focal point of any story. Stories begin and end with women'.

- The role the plays served

With the above quote very important insight into the role of Greek theatre is portrayed, namely that it was not merely a mirror of society conveying 'a number of social and political facts of that time', but that it had a purpose of challenging the society and that ' $(\mathrm{t})$ here was always the writer/play that, in its genre, did not "comply with" the norms of Greek theatre \& society".

- Relevant related concepts

Together with the insight into the role and themes of the plays, the teaching approach seems to have facilitated understanding of concepts such as 'feminism' and 'the male gaze'. One student-respondent go even further by not only claiming insight into the concept (the 'male gaze' in this case), but moreover an ability to identify it in other contexts (an ability to apply knowledge gained): 'A knowledge and understanding of the male gaze and how to view and read the gaze into works of art of all kinds'.

Underlying all the insights into Greek plays discussed above, is an insight into the Ancient Greek culture and society.

- Ancient Greek culture and society

In this case study, although none of the research questions hint towards learning about ancient Greek culture and society, many responses refer to knowledge that was gained about the socio-historical context of the ancient Greek. The students in particular seem to have gained a better understanding of: ancient Greek theatre, culture, society, religion, ways of living, traditions, beliefs, values, social political contexts, motives for revenge, the justice system and the moral psyche of classical Greek drama.

The above confirms that the first three course outcomes (stated under 'Course outcomes' above) had most certainly been addressed. In line with constructivist design, the approach used to achieve them does not encourage regurgitation or a mere knowing and understanding of facts. The knowledge that the students gained (as described in this section) are applied and a number of skills form part of this learning experience as discussed below.

\section{Skills gained}

The skills that students seem to have acquired during the whole experience, as derived from the data, can be divided into three categories, namely academic skills, interpersonal skills and drama-related skills.

\section{Academic skills and authentic intellectual work}

Certain academic skills were required for this module, under which self study, critical thinking, prior preparation and research. Many responses indicated that these were 
indeed achieved. The following is but one example: 'Instead of being spoon-fed, we had to do research ourselves and learn how to apply the research'.

The research, however, was not a goal in itself. Students had to apply their newly gained knowledge and this in itself required a number of skills that emerged very clearly from the data. Theory and practice had to be linked. This required them to investigate and question values and ideas from society. It also challenged them to think creatively, considering different points of view - both in terms of the group work and in terms of the different viewpoints portrayed by the different plays. Furthermore '...the intricacies of taking a text and manipulating it into a new concept...' (synthesis and text adaptation) '. . allowed for a deeper understanding of the play and the characters'. This in itself created opportunities for the development of abilities such as critical and symbolic thinking, as well as engaging with the discipline and task at hand (including analysis, interpretation and contextualisation of plays). In terms of future relevance, one student remarked: 'Contextualisation and interpretation of the theories given to you is important in my field of study and this module refined skills that accompany the interpretation of text'.

The set of skills described above, as well as the mention of their future relevance stress the fact that the learning nourished here is more than a mere compliance with course outcomes. Knowledge was constructed, manipulated and used to get to an in depth understanding of the plays and their significance for today. Products in the form of performances contributed to the learning of all learners - extending the value beyond demonstration of personal success. This indeed reflects what Scheurman and Newmann (1998) and Newmann (2000) calls 'authentic intellectual work' (discussed earlier) in that the whole process requires advanced cognitive engagement and results in 'personally, aesthetically or socially useful products'.

\section{Interpersonal skills}

All of the above was achieved in a social learning environment with peers playing a central part in the 'meaning making' process - true to a Vygotsky (1978) perspective of social constructivism. This challenged students to put into practice a number of interpersonal skills including '... knowledge and insight into working together as a group'. The research and play adaptations in groups forced the students to approach a task and a text from different perspectives, which in turn required perseverance, patience, as well as tolerance and openness to different ideas and 'other peoples opinions and point of views'.

\section{Drama-related skills}

Apart from the richness of the cognitive engagement and the interpersonal skills as described above, a number of different drama-related skills were addressed as well. By incorporating performance and participation in the classes the students developed and applied different skills from improvisation/adaptation to play writing, acting and producing a play. 


\section{Attitudinal and emotional gains}

Without a sound emotional and attitudinal disposition, it might have been very difficult for any of the above cognition and skills to have been gained. Gravett (2004, 38) places a high price on the role of emotion in learning when she states that ' $\ldots$ our single-most important role as teachers, and the most difficult, might be to inspire student attention to, and interest in, learning the core ideas of our disciplines'. She continues to explain the complexity of this task by highlighting that 'the challenge for teachers is to create learning environments in which there is a healthy balance between support, interest, enjoyment and challenge' (Gravett 2004, 39). The use of a form of art in this case (the performance of play adaptations) seems to have achieved exactly this end.

According to students' responses this educational experience where there were indeed a balance between support, interest, enjoyment and challenge, clearly contributed to their development on an affective level. They claim to have acquired an appreciation for the complexity, diversity and role in society of ancient Greek plays - their entertainment value, relevance for today and contribution to literature. They also appreciated the educational context, the effort that went into the productions, their fellow students and themselves by recognising their own abilities on the one hand and their shortfalls on the other

The complete educational experience seems to have given students an opportunity to reflect and become aware of themselves as individuals within a particular context. According to quite a number of responses the experience taught them 'how to take responsibility' for self and others. One response reflects a self-insight which can be as much as one could have hoped to achieve with the module:

I once again realized where my passion for drama comes from - within myself - and to learn the origins of theatre and drama was an amazing experience.

Although most students found this approach enjoyable, it must be mentioned that some students found it time-consuming as well. This, however, was often mentioned within a context of the overall value added by the course.

\section{Value added to learning}

Within a tertiary environment where academic success is increasingly linked to economic and financial gains, one of the questions that comes to mind at the discussion of any innovation, is whether it contributed to better throughput and higher marks. In this study it was not possible to link the innovation with higher student marks than in previous years. Yet it created an opportunity that was 'full of learning experiences'. In this regard (Jensen 2001, vi) notes that 'integrating the arts into every subject you might not get the high test scores immediately'. He is, however, of the opinion that this is counterbalanced by something that has far greater value:

... you may get fewer dropouts, higher attendance, better team players, an increased love of learning, greater student dignity, enhanced creativity, a more prepared citizen for the workplace of tomorrow, and greater cultural awareness as a bonus. 
The argument is echoed by Scheurman and Newmann $(1998,1)$ who believe that '(a)uthentic intellectual achievement consists of more than the ability to do well on an academic test'. With the array of knowledge, skills and attitudes described above we concur that the holistic development of the individual can never be confined to or reflected by a single score.

Apart from the knowledge, skills and attitudes described above, there was additional value added to the learning experience as a whole:

- Relevance

Various responses point towards how the teaching approach created an environment in which that which was 'foreign' to the students could be de-mistified and brought to their 'level of understanding' - up to a point where students experienced the studying of Greek plays to be relevant and felt that 'the information learned... (could be) applied practically later in life'.

\section{- Better understanding}

According to Hannaford $(1995,88)$ '(a)rtistic expression is immensely valuable to overall personal development and cognitive understanding'. Numerous responses indicate that students feel they have gained a better understanding of Greek plays, the related concepts, as well as '... of what was going on in lectures'. An analysis of these responses shows that the following aspects in particular facilitated this improved understanding: the interactivity; the active engagement with the plays (both by watching them and being part of them); as well as relating the plays to current realities through adaptation.

In this context it should, however, be mentioned that a few students would have preferred more time to be spent on discussing the original text and context of the plays.

- Easy learning and remembering

Students found it easier to learn and remember 'the plot, themes and other aspects' of the plays, since the adaptations were visual and resonated with their learning styles. They therefore understood the original plays better and found it interesting since they were practically engaged and had ownership of the knowledge they created themselves.

This is a clear demonstration of the argument put forward by Burnaford, April, and Weiss (2001) that '(the) arts function as a way of committing concepts and content to memory'. They furthermore state that:

(t)hese indelible sensory images mark and organize information and concepts in a way that allows learners to access and apply new knowledge. (11-12)

This 'making' and 'organising' of information might also be the reason why two respondents indicated that they have found 'new ways to study' and 'how to study differently'. 
All of the above contributed to a learning environment that fosters true deep learning beyond knowledge and remembering.

- Deep learning

Current research which links academic and social development with learning in the arts (Bresler 2007; Deasy 2002; Jensen 2001) strongly suggests that the arts provide strategies for deepening the learning experience. The academic competencies in the preceding sections indicating depth of learning in a way that links with the constructivist views of Scheurman and Newmann (1998) and Newmann (2000). This deep constructivist learning is nicely summarised by the following response from one of the students:

Being able to deconstruct a current text and re-create a story, formulating through lines. Abstract thinking and how to work with individuals with different view points, collaborating and producing a concept that everyone can say contributed.

\section{Conclusion}

Jensen $(2001,2)$ believes that: 'arts enhance the process of learning. The systems they nourish, which include our integrated sensory, attentional, cognitive, emotional, and motor capacities are in fact, the driving forces behind all other learning'. He furthermore believes that the arts 'provide learners with opportunities to simultaneously develop and mature multiple brain systems' (Jensen 2).

In this article we have tried to demonstrate that, by careful reframing of the learning environment - even within learning material perceived by students as 'boring' and 'foreign' - it is possible to achieve a rich learning experience in which multiple brain systems are developed. This case study describes a teaching approach that links teaching ancient art (Greek plays) with current drama and performance practices - integrating arts and teaching in a way that brings the classical content to life. Conceptually situated within the theoretical framework of Heathcote's (Heathcote and Bolton 1995) 'mantle of the expert', the teaching design of the approach answers to all areas of learning design as defined by Boud and Prosser's (2002, 240-241). Furthermore all aspects of what Newmann (2000) refers to as 'authentic intellectual work' brings depth to the educational experience - assuring that it is not only memorable, but truly useful and applicable to the students within their particular context - during and after tertiary studies.

The result is a rich learning experience that surprises by leading to outcomes far beyond those specified in the curriculum statement for the modules. Outcomes at cognitive, skills as well as emotional/attitudinal levels have been described as they emerged from the qualitative research data.

In this instance the answer did not lie in the change of content or subject matter (the classics remain the classics). Neither did it involve supplementary intervention to improve student skills or academic abilities. With careful re-planning and reframing of the learning space the content came to life. A qualitative analysis of student comments suggests a rich learning experience, including enjoyment, improvement of knowledge and skills, as well as positively changed attitudes. 


\section{References}

Biggs, J. 1999. Teaching for quality learning at university. Buckingham, UK: Society for research in Higher Education/Open University Press.

Boud, D., and M. Prosser. 2002. Appraising new technologies for learning: A framework for development. Educational Media International 39, no. 3: 237-45.

Bresler, L., ed. 2007. International handbook of research in arts education. Dordrecht, the Netherlands: Springer.

Burnaford, G., A. Aprill, and C. Weiss, eds. 2001. Renaissance in the classroom: Arts integration and meaningful learning. London: Lawrence Erlbaum Associates.

Coetzee, M-H., M. Munro, and A. de Boer. 2004. Deeper sites through various lines: LMS and whole brain learning in body/voice training for performers in the HET band. The South African Theatre Journal 18: 134-57.

Deasy, R.J., ed. 2002. Learning in the arts and student academic and social development. Washington, DC: Arts Education Partnership.

Freire, P. 2006. Pedagogy of the oppressed. 30th Anniversary ed. New York: Continuum.

Gravett, S. 2004. Enhancing teaching through an exploration of the biology of learning. In Teaching and learning in higher education, ed. S. Gravett and H. Pretoria Geyser, 32-40. South Africa: Van Schaick.

Hannaford, C. 1995. Smart moves: Why learning is not all in your head. Salt Lake City, UT: Great River Books.

Heathcote, D., and G.M. Bolton. 1995. Drama for learning: Dorothy Heathcote's mantle of the expert approach to education. Portsmouth, UK: Heinemann.

Henning, E. 2004. Finding your way in qualitative research. Pretoria, South Africa: Van Schaik.

Herrmann, N. 1996. The whole brain business book. New York: McGraw Hill.

Jensen, E. 2001. Arts with the brain in mind. Alexandria, VA: Association for Supervision and Curriculum Development.

Mayes, T., and S. de Freitas 2004. JISC e-learning models desk study, Stage 2: Review of e-learning theories, frameworks and models. http://www.uwic.ac.uk/ltdu/docs/Review $\% 20 \mathrm{of} \%$ 20e-learning\%20theories.pdf (accessed August 10, 2010).

Mighty, J. 2009. Double jeopardy: The risks of action and inaction in international higher education in the 21st century. Keynote address delivered at the HELTASA conference: Risk and resilience in higher education, November 25-27, in University of Johannesburg, South Africa.

Newmann, F.M. 2000. Authentic intellectual work: What and why? Center for Applied Research and Educational Improvement Research/Practice Newsletter 8, no. 1. http://www.cehd.umn. edu/carei/reports/rpractice/Fall2000/newmann.html\#2 (accessed March 14, 2011).

Scheurman, G., and F.M. Newmann 1998. Authentic intellectual work in social studies: Putting performance before pedagogy. Silver Spring, MD: National Council for the Social Studies. http://www.learner.org/workshops/socialstudies/pdf/session4/4.AuthInellectualWork.pdf.

South African Qualifications Authority (SAQA). 2005. Developing learning programmes for NQF-registered qualifications and unit standards. Pretoria, South Africa: SAQA.

Vygotsky, L.S. 1978. Mind in society: The development of higher psychological processes. Cambridge, MA: Harvard University Press.

Zeeman, E. 2010. Study guide: Drama and film studies 2010. Pretoria, South Africa: Univ. of Pretoria.

Zuber-Skerrit, O. 1992. Professional development in higher education - A theoretical framework for action research. London: Kogan Page. 